\title{
СОЦИАЛЬНАЯ ОБУСЛОВЛЕННОСТЬ УГОЛОВНОЙ ОТВЕТСТВЕННОСТИ ЗА ПРЕСТУПЛЕНИЯ, СВЯЗАННЫЕ С НЕПРАВОМЕРНЫМ ПРИМЕНЕНИЕМ СОТРУДНИКАМИ ОВД ОГНЕСТРЕЛЬНОГО ОРУЖИЯ
}

\section{SOCIAL CONDITIONALITY OF CRIMINAL RESPONSIBILITY FOR CRIMES RELATED TO THE ILLEGAL USE OF FIREARMS BY POLICE OFFICERS}

\section{Zelyutin}

Summary. This article examines the impact of the social foundations of society on the involvement of police officers to criminal responsibility for crimes related to the illegal use of firearms. The legislation of the Russian Federation regulating the activities of the police and establishing the limits of the performance of their official duties by the police officers was studied.

Keywords: police, law, social control, crime, abuse, firearms, powers.
Зелютин Михаил Александрович

Адъюнкт, ФГКОУ ВО «Уральский юридический институт Министерства внутренних дел Российской Федерации», г. Каменск-Уральский zelmike96@yandex.ru

Аннотация. В настоящей статье рассматривается влияние социальных основ общества на привлечение сотрудников ОВД к уголовной ответственности за преступления, связанные с неправомерным применением огнестрельного оружия. Изучено законодательство РФ, регулирующее деятельность полиции и устанавливающее пределы исполнения сотрудниками ОВД своих должностных обязанностей.

Ключевые слова: полиция, закон, социальный контроль, преступление, превышение, огнестрельное оружие, полномочия. овременное общество представляет собой достаточно сложный конгломерат социальных, политических, правовых и иных отношений, которым свойственны различные системы ценностей, идей и убеждений. В этой связи актуальным является вопрос социальной обусловленности и обеспечения социального контроля уголовной ответственности.

Концепция социального контроля появилась в связи с потребностью и способностью общества обеспечить социальный порядок без опоры на силу или насилие. В рамках этого широко понимаемого понятия социальный контроль в первую очередь рассматривает социальное состояние общества, которое опирается на относительно высокую степень согласия и гармоничные социальные отношения. В широком понимании социального порядка подразумевается, что все социальные институты в обществе выполняют функцию инструментов социального контроля. В этой связи применительно, например, к борьбе с преступностью, социальный контроль рассматривается как обусловленная социальная реакция на преступность, функционально ориентированная на восстановление социальной интеграции по- средством различных институтов контроля, таких как полиция, суды и наказания.

Подобный подход к социальному контролю опирается на социологию Т. Парсонса [5], который разработал теорию социального контроля как следствие теории девиантности и преступности. В частности, у него социальный контроль понимается как реинтегрирующая попытка стабилизировать функционирование общества, а механизмы социального контроля функционируют для удовлетворения интегративных потребностей общества в обеспечении стабильности.

В этой связи применимость социального контроля в рамках настоящей статьи обуславливается его центральной функцией, которая состоит в том, чтобы обеспечить гармоничное взаимодействие между различными членами общества. Особенно важно это в условиях социального порядка, который предполагает высокую степень социальных различий и возрастающую дифференциацию в экономическом и других соответствующих аспектах. Это исходит из того, что социальный контроль включает в себя различные механизмы интеграции, на- 
правленные на обеспечение порядка и стабильности на социальном уровне, что достаточно актуально в условиях усиления тенденции роста индивидуализма и культурного разнообразия.

Как составную часть социального контроля можно выделить социальную обусловленность определенных тенденций и явлений, возникающих и протекающих в жизнедеятельности общества. Именно с помощью социального контроля становится возможным определить социальную обусловленность процессов, проистекающих в обществе, в том числе - в области применения мер юридической ответственности.

Поскольку, выступая как органически присущая современному обществу функция, социальный контроль затрагивает функционирование различных социально-политических институтов. В этой связи можно говорить о существовании такой разновидности контроля как государственный контроль, представляющий собой действенное средство правовой политики.

Цель государственного контроля - это процесс обеспечения достижения государством конкретных результатов его работы или конкретных результатов работы органов и системы государства. Сложность и многогранность контрольной деятельности определяют многообразие целей и методов контроля, что дает возможность широко классифицировать его виды.

В рамках реализации уголовно-процессуальных отношений особое место занимает ведомственный контроль, который выступает в качестве специфических форм реализации специально уполномоченными органами государственного контроля. И именно данные органы должны осуществлять свою деятельность исключительно в рамках закона. Конечно, их деятельность направлена на обеспечение эффективности расследования уголовных дел, связана с использованием всего арсенала криминалистической поддержки раскрытия, расследования и предупреждения преступлений. Недопустимым является превышение должностных полномочий, таких, например, как неправомерное применение сотрудником ОВД огнестрельного оружия. Во всех демократических обществах полиция должна нести ответственность за то, что она делает или не делает, и за тактику, которую она часто использует при выполнении своих обязанностей.

На уровне нормативного правового регулирования базовые положения, формализующие ведомственный контроль и минимизирующие неправомерные действия сотрудников ОВД включены в текст УПК РФ [2], ими определяется процессуальная форма контроля. В свою очередь, межведомственные и ведомственные норма- тивные правовые акты способствуют развитию и детализации обязанностей и деятельности указанных лиц. При этом поведенный анализ указанных положений свидетельствует о том, что в качестве предмета нормативного правового регулирования выступает организационно-управленческая деятельность.

Поэтому в качестве основных задач контроля, осуществляемого, например, сотрудниками ОВД, можно определить:

- обеспечение выполнения требований нормативных правовых актов в части осуществления досудебного расследования;

- оказание необходимого содействия в устранении выявленных недочетов в работе;

- обеспечение качественного принятия и исполнения управленческих решений подчиненными;

- повышение уровня оперативной, организационной и следственной деятельности в подразделении;

- обеспечение подбора, расстановки и постоянной оценки деятельности сотрудников подразделений и др.

Как мы видим, полномочия сотрудников ОВД регламентированы и любое нарушение может повлечь привлечение к юридической ответственности. Например, к уголовной ответственности за преступления, связанные с неправомерным применением сотрудниками ОВД огнестрельного оружия. В соответствии со ст. 18 Федерального закона от 7 февраля 2011 г. N3-Ф3 «О полиции» [3] (далее - Закон о полиции) сотрудник полиции имеет право на применение физической силы, специальных средств и огнестрельного оружия по основаниям и в порядке, которые предусмотрены гл. 5 вышеуказанного нормативного правового акта.

Изучение судебной и следственной практики показывает, что действия сотрудников полиции, неправомерно применивших огнестрельное оружие, чаще всего квалифицируются по п. «а» ч. 3 ст. 286 УК РФ [2] как превышение должностных полномочий, совершенное с применением насилия. Иногда дополнительно по пп. «б» и (или) «в» той же части, предусматривающим, соответственно, признаки применения оружия или специальных средств, причинения тяжких последствий.

В результате проведенного нами анализа правоприменительной практики были выявлены определенные проблемы в рассматриваемой области.

Так, например, вопрос о том, какие последствия для жизни и здоровья учтены в ст. 286 УК РФ, в теории уголовного права до настоящего времени не получил однозначного разрешения. Высказываются аргументы «за» 
и «против» учета санкций при осуществлении квалификации сложного насильственного преступления. Между тем судебная практика идет по пути их учета, руководствуясь правилом, что содеянное квалифицируется по совокупности преступлений, если причинение вреда здоровью влечет более строгое или равное наказание, чем то, которое предусмотрено нормой о сложном насильственном преступлении [4. С. 112].

Далее, другой важный момент связан с пределами допустимости применения насилия. Указанные пределы представляют собой нормативно предусмотренные рамки интенсивности применяемого насилия в тех случаях, когда его применение разрешено.

Закон о полиции устанавливает следующие пределы:

- при применении насилия сотрудник полиции обязан стремиться к минимизации любого ущерба (ч. 3 ст. 19 Закона о полиции);

- сотрудники полиции вправе использовать только то огнестрельное оружие, боеприпасы и специальные средства, которые содержатся в перечне, утвержденном Правительством РФ (ч. 2 ст. 18 Закона о полиции).

Насилие и угрозы нередко сопровождаются применением оружия и специальных средств, то есть умышленными действиями, связанными с использованием сотрудником полиции поражающих свойств указанных предметов или использованием их по назначению. Удары оружейными прикладами рассматриваются как применение оружия, поскольку они по своим конструкторским свойствам не только имеют эргономичное значение, но и используются в качестве оружия ближнего боя. Удары частями оружия, не имеющими поражающих свойств (например, стволом автомата), не могут квалифицироваться как применение оружия.

В завершение сделаем вывод о том, что, по нашему мнению, влияние социальных институтов на развитие и функционирование института уголовной ответственности представлено комплексом стратегий, процедур и мероприятий, призванных гарантировать, что ситуация не выйдет из-под контроля.

В свою очередь, применение ведомственного контроля позволяет регулировать действия руководителей подразделений ОВД в части руководства деятельностью сотрудников ОВД с учетом ожидаемого результата. Таким образом, обеспечивается необходимое направление или мотивация для достижения запланированных целей и осуществление эффективной правоохранительной деятельности в будущем. Это также достигается за счет корректировки ошибок в деятельности сотрудников ОВД и принятия корректирующих мер таким образом, чтобы отклонения от стандартов были минимизированы и заявленные цели организации правомерной работы полиции были достигнуты желаемым образом.

\section{ЛИТЕРАТУРА}

1. Уголовный кодекс Российской Федерации от 13.06.1996 N63-Ф3 (ред. от 30.12.2020) (с изм. и доп., вступ. в силу с 01.03.2021) // С3 РФ. 1996. N25. С. 2954.

2. Уголовно-процессуальный кодекс Российской Федерации от 18.12.2001 N174-Ф3 (ред. от 24.02.2021) // СПС «Консультант Плюс».

3. Федеральный закон от 07.02.2011 N3-Ф3 (ред. от 24.02.2021) «0 полиции» (с изм. и доп., вступ. в силу с 01.03.2021) // С3 РФ. 2011. N7. Ст. 900.

4. Иногамова-Хегай Л.В. Концептуальные основы конкуренции уголовно — правовых норм: Монография. М.: НОРМА, ИНФРА-М, 2015. 288 С.

5. Parsons, T. The Social System. New York: The Free Press. 1951. 